\title{
Chapter 8 \\ Forest Green Infrastructure to Protect Water Quality: A Step-by-Step Guide for Payment Schemes
}

\author{
Thomas R. Nisbet, Maria-Beatrice Andreucci, Rik De Vreese, Lars Högbom, \\ Sonja Kay, Mary Kelly-Quinn, Alessandro Leonardi, Mariyana I. Lyubenova, \\ Paola Ovando Pol, Paula Quinteiro, Ignacio Pérez Silos, and Gregory Valatin
}

\author{
T. R. Nisbet $(\bowtie) \cdot$ G. Valatin \\ Forest Research, Alice Holt Lodge, Farnham, UK \\ e-mail: tom.nisbet@forestresearch.gov.uk
}

\section{M.-B. Andreucci}

Department of Planning, Design, Technology of Architecture, Faculty of Architecture, Sapienza

University of Rome, Rome, Italy

R. De Vreese

Independent Researcher and Consultant in Urban Forestry and Ecosystem Services, Ghent, Belgium

\section{Högbom}

Forestry Research Institute of Sweden (Skogforsk), Uppsala, Sweden

S. Kay

Agroscope, Research Division Agroecology and Environment, Research Group Agricultural Landscapes and Biodiversity, Zurich, Switzerland

M. Kelly-Quinn

School of Biology and Environmental Science, University College Dublin, Dublin 4, Ireland

A. Leonardi

ETIFOR | Valuing Nature, Padova University Spin-off, Padova, Italy

M. I. Lyubenova

Department of Ecology and Environmental Protection, University of Sofia "St. Kliment Ohridski", Sofia, Bulgaria

P. O. Pol

The James Hutton Institute, Aberdeen, UK

P. Quinteiro

Centre for Environmental and Marine Studies (CESAM), Department of Environment and Planning, University of Aveiro, Aveiro, Portugal

I. P. Silos

Environmental Hydraulics Institute, Universidad de Cantabria, Santander, Spain

F. Nakamura (ed.), Green Infrastructure and Climate Change Adaptation, Ecological Research Monographs, https://doi.org/10.1007/978-981-16-6791-6_8 


\begin{abstract}
This chapter describes how to design appropriate and cost-effective forest green infrastructure for water payment schemes to protect and improve water quality. It is structured by the main steps involved in establishing a payment scheme, starting with identifying the water issues and how tree planting and forest management can help, managing potential disbenefits and exploring multiple benefits, followed by scheme design, monitoring and communication. The approach is relevant to all actors involved in sustainable water management, farming and forestry, from policy makers, catchment planners and land managers to private investors, practitioners and local communities. We provide a common language and framework to help ensure schemes are successful in delivering water and other ecosystem services while minimising possible trade-offs (such as the potential for tree planting to reduce water resources).
\end{abstract}

Keywords Forest green infrastructure - Forests for water · Diffuse pollution · Payments for ecosystem services · Sustainable water management

\title{
8.1 Introduction
}

The main aim of European Union (EU) water policy is to ensure that a sufficient quantity of good-quality water is available for both people's needs and the environment. Despite ongoing efforts by Member States to improve water status, only $40 \%$ of surface waters (rivers and lakes) are in good ecological status or potential (EEA 2018). Diffuse pollution is a major pressure, dominated by agricultural sources in the form of excessive emissions of nutrients (nitrates and phosphates), pesticides, sediment and faecal indicator organisms (FIO) (Fig. 8.1). Agriculture is estimated to contribute to $25 \%$ of surface water bodies failing good ecological status, and is the main cause of groundwater bodies failing to achieve good chemical status (EEA 2018).

Member States continue to develop and invest in best practice farming measures to reduce diffuse pollution from agriculture, such as farm-level nutrient planning, reduced tillage and the use of catch crops. These have improved water quality but in most cases by an insufficient margin to meet environmental quality standards. Notably, there has been limited improvement in the proportion of water bodies achieving good ecological status since the first River Basin Management Plans were published in 2009 (EEA 2018). While there is scope for further improvement in the effectiveness and uptake of farm measures, there is a growing recognition that wider delivery of good ecological status will only be achieved by a significant degree of land-use change (Stutter et al. 2012). This chapter focuses on the water benefits of forest green infrastructure (FGI), although it is recognised that the use of tree-based measures such as tree planting and management should be part of a wider framework of integrated catchment management (e.g. including opportunities for peatland and wetland restoration) and associated strategies and plans. 


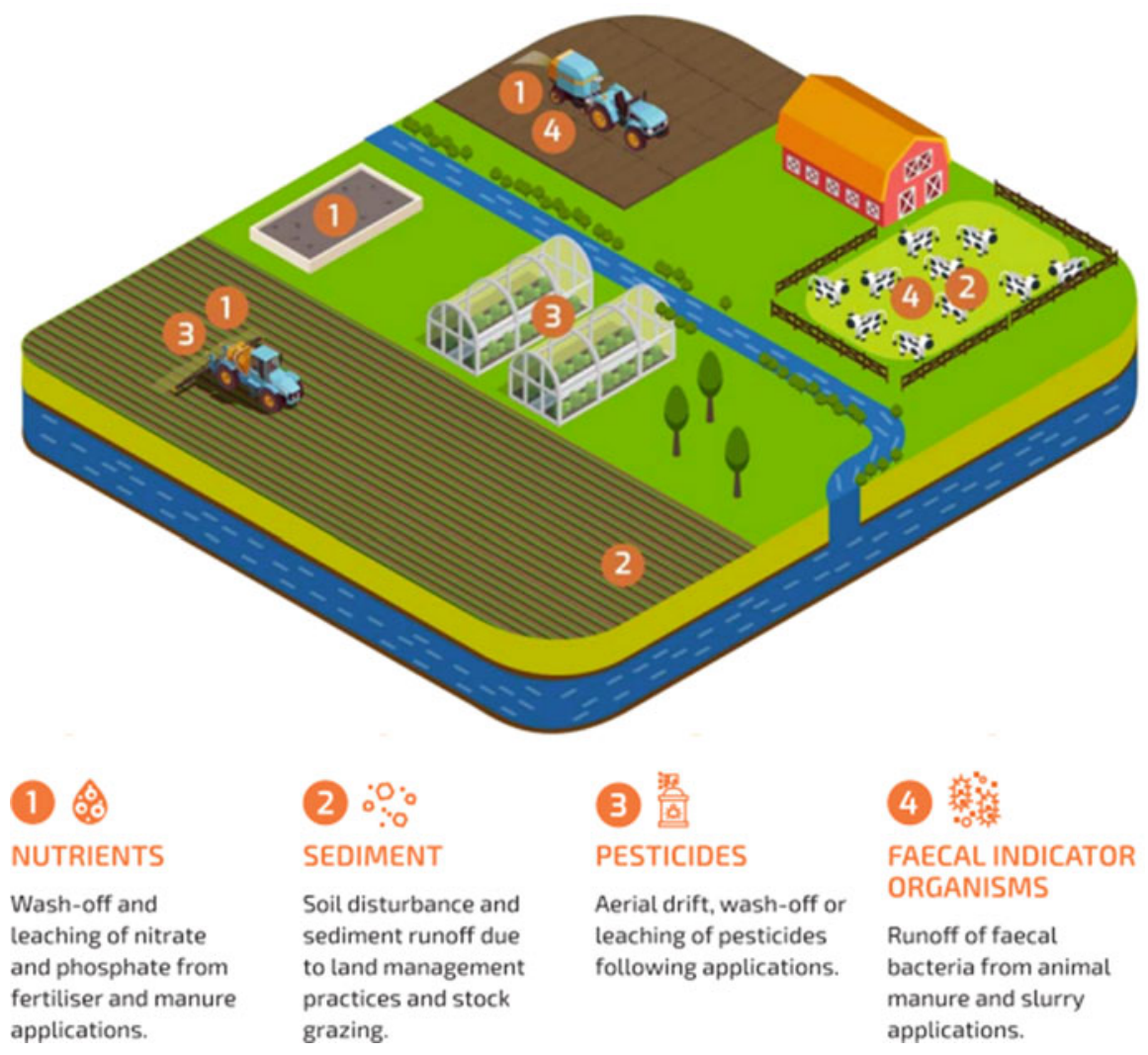

Fig. 8.1 Catchment sources and pathways of agricultural diffuse pollution impacting on the water environment and water users

The multiple benefits provided by FGI in the form of trees, woodlands and forests (the terms woodlands and forests are used throughout the document and describe land predominantly covered by trees; woodland means a relatively small area of trees, while forest refers to a large tract of trees) are increasingly recognised and valued for society. Benefits for the water environment include the ability to protect aquatic habitats and species from disturbance, preserve the quality of drinking water, alleviate flooding and guard against erosion, landslides and the loss of soil (Nisbet et al. 2011). Tree planting provides a very effective and relatively secure measure for tackling agricultural diffuse pollution, in addition to helping with carbon storage and providing other environmental benefits. Small-scale, targeted use of FGI such as planting of woodlands on or around pollutant sources, or along pollutant pathways in the form of 'woodland buffers', offers a smart way of attenuating or eliminating pollutant delivery to surface waters and groundwaters while minimising land take and impacts on food security. 
Although the benefits of FGI for water are well known (Creed and Noordvijk 2018), progress is highly constrained by the significant cost to landowners and managers in terms of reduction in land value and agricultural income resulting from land-use change. This is especially the case for tree planting on the more productive and intensively managed agricultural land that represents the greatest source of diffuse pollutants. Achieving enough tree planting to make a difference for water body status will require better incentives in the form of payments for the water and other ecosystem services provided. Maintaining and protecting the water benefits provided by existing FGI may also require funding support, especially if changes to forest design and management are needed to address threats posed by climate change.

There are many different types of payment for ecosystem services (PES) schemes, and the approach and definitions continue to evolve (Forest Europe 2019). The main purpose of PES is to protect and enhance the provision of ecosystem services for environmental gain and better management of natural resources by incentives (Gatto et al. 2009). Ideally, five conditions should be met in a PES scheme, which are: (1) the identification of a well-defined ecosystem service to be exchanged, in this case principally targeted tree planting and the appropriate management of new or existing woodlands and forests to improve water quality; (2) the presence of at least one service buyer and (3) at least one seller; (4) the voluntary nature of the marketing of the ecosystem service; and finally, (5) the conditionality of the payment, requiring the seller/provider to ensure that the expected benefit is delivered and sustained over time. Often these conditions are not met, especially condition 4 , such as where schemes are implemented within a compulsory regulatory framework. Such cases are often referred to as 'PES-like' schemes.

We adopt a broad definition of a FGI for water payment scheme based upon three criteria: (1) a transfer of resources between at least two stakeholders; (2) a transaction explicitly targeted at obtaining water-related services; and (3) a payment for actions related to trees, either primarily for water services or for bundled (including water) ecosystem services.

\subsection{Identifying the Problem}

As a consequence of the introduction in 2000 of the EU Water Framework Directive (WFD), there is now far greater knowledge about the water environment across Member States. Regular monitoring and assessment of surface- and groundwaters at more than 130,000 sites has generated a detailed understanding of the condition of Europe's water bodies, as well as of the pressures that are preventing the majority achieving the targets of good ecological status or potential (Fig. 8.2).

National water regulators compile and regularly update datasets and maps showing which water bodies are at less than good status, the causal activities and progress made with introducing programmes of measures to achieve target status. 

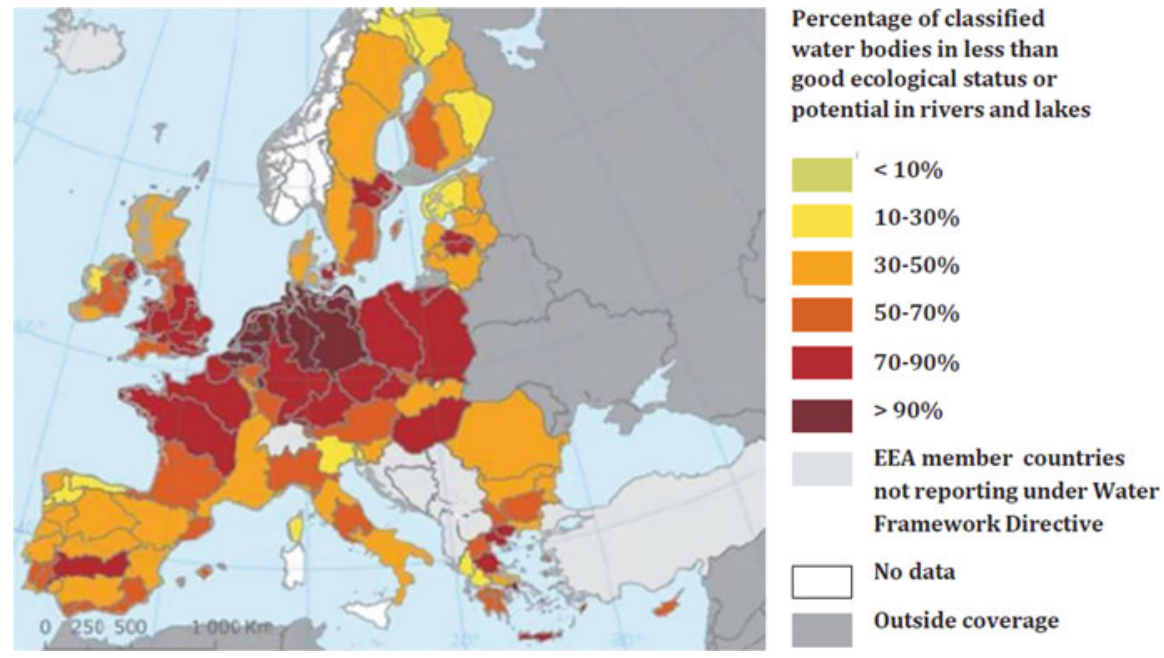

Fig. 8.2 Proportion of surface water bodies by Member State at less than good ecological status. Reproduced from EEA (2016) @ European Environment Agency, 2016

This includes knowledge of which water bodies are failing good status due to diffuse pollutants such as nutrients, sediment and pesticides derived from agriculture, as well as impacted by other anthropic pressures on water (Fig. 8.3). Water regulators also have information on the location and condition of particularly sensitive waters, such as drinking water protected areas and high-status waters supporting priority habitats and species. These data are submitted to the European Environment Agency (EEA) at regular intervals to allow an assessment of the status and pressures acting on European waters, with the last assessment published in 2018 (EEA 2018).

Addressing water pressures and achieving water targets requires co-ordinated and long-term actions at the level of the catchment or sub-catchment of the water body. This is particularly the case with managing diffuse pollution, which often has a variety of sources spread across the landscape and land ownerships. In some regions and countries, pollutant models have already identified pollutant sources and pathways to aid targeting of measures (Collins et al. 2018; Mockler and Bruen 2018). Catchment partnerships have been formed in many Member States to adopt an integrated, catchment-based approach to tackling polluting activities and delivering improvements. Partnerships are often led by trusted intermediaries who are better able to achieve change on the ground supported by co-ordinated funding bids (ribblelifetogether.org/improve/woodlands, wrt.org.uk/project/3riversproject, www.woodlandsofireland.com, www.etifor.com/en/studies-and-research). 


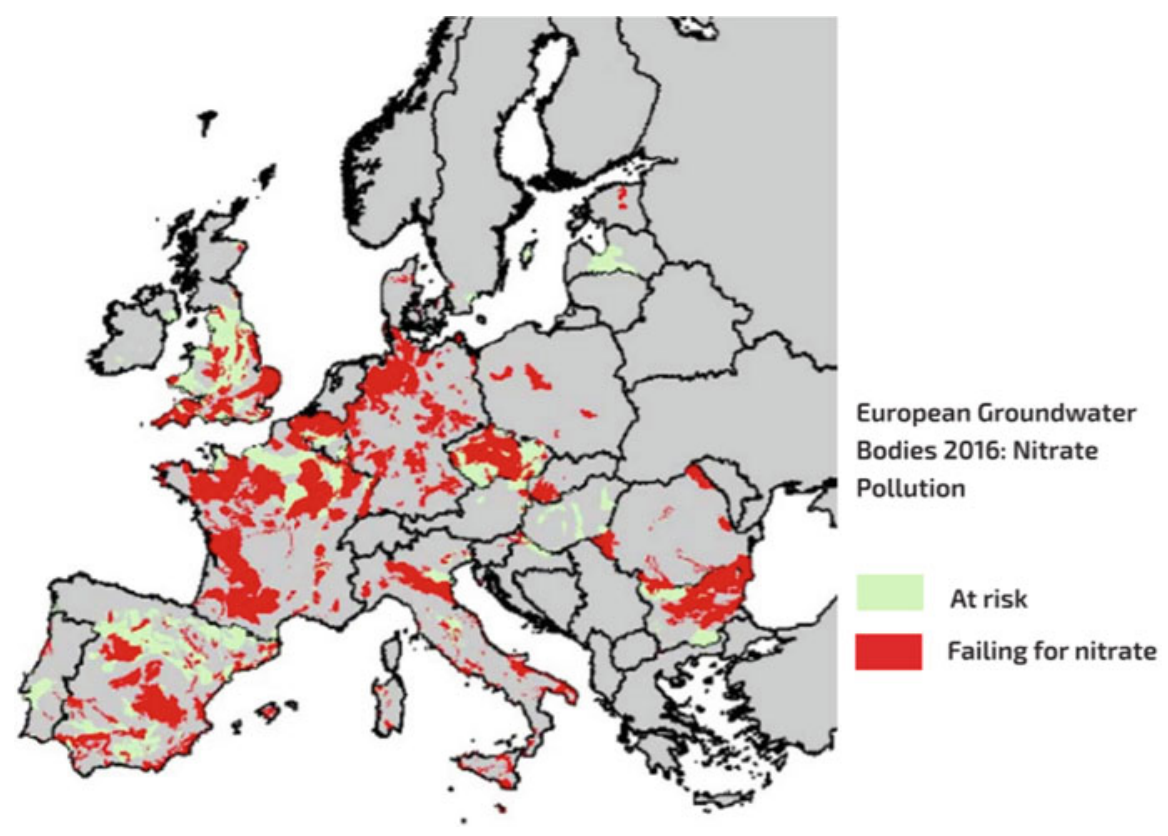

Fig. 8.3 Distribution of groundwater bodies across Member States failing for nitrate

\subsection{Role of Opportunity Mapping}

Opportunity mapping can help identify and prioritise water bodies and component areas of land for targeting FGI to reduce water pressures (Broadmeadow and Nisbet 2012). Evidence-based planning supports integrated catchment management, and the maps guide and underpin the development of FGI for water PES (PESFOR-W) schemes. This approach is based on using geographic information systems (GIS) and integrates a wide range of spatial datasets to determine the most effective locations for changing land use and management, to meet WFD targets and generate multiple benefits for society (Box 8.1).

The key steps involved in evidence-based planning are summarised below:

1. Use WFD datasets to identify boundaries of surface and groundwater bodies failing good ecological or chemical status due to diffuse pollution from agriculture; determine which and how many diffuse pollutants are causing failure, either through WFD measurements in relation to water chemical or biological standards or an assessment of risk.

2. Draw on any available statistics (e.g. from agricultural inventories, or surveys of fertiliser, or pesticide use), site surveys and measured or modelled pollutant data to identify and rank the spatial sources and pathways of each diffuse pollutant draining to the contributing catchments. 


\section{Box 8.1 Opportunity Mapping to Reduce Diffuse Pollution and Flood Risk in England and Wales}

Opportunity mapping was applied to England and Wales in 2014 to better target grant aid and private investment for FGI to help deliver positive outcomes for water quality and flood risk management. The mapping used national datasets of modelled pollutant loads and pressures at a $1 \mathrm{~km}^{2}$ scale for each of phosphate, sediment, nitrate, total pesticides and faecal indicator organisms. These were overlaid with datasets on the risk of flooding from rivers, including on the propensity of soils to generate rapid runoff. Target areas for woodland creation were identified based on the scope to reduce one or more diffuse pollutants and contribute to flood risk management (the colours on the map and the associated values in the key refer to the number of diffuse pollutants that tree planting could benefit in a given location).The maps were subsequently used to score water benefits to inform planting applications and Rural Development Programme grant support.

For further information, see www.forestresearch.gov.uk/research/foresthydrology/opportunity-mapping.

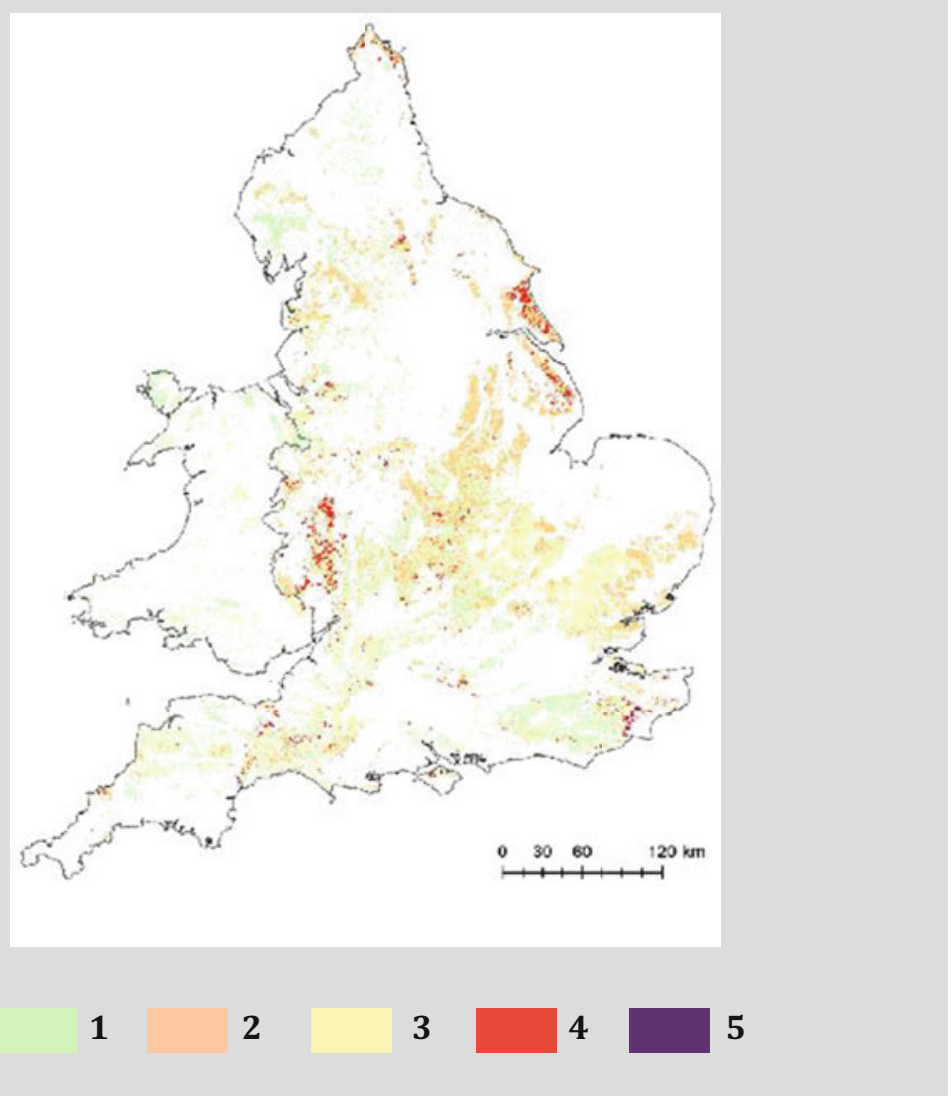


3. Map any spatial constraints (e.g. designated open habitats or archaeological features) and sensitivities (e.g. landscape views) to FGI within the catchments; overlay spatial datasets to identify pollutant hotspots free of constraints to FGI where there are opportunities for woodland creation to reduce one or more diffuse pollutants in failing water bodies.

4. Consider and map any other water issues that could benefit from FGI (e.g. local downstream communities or assets at flood risk) and overlay these to determine scope to deliver multiple benefits through tree planting where there is greatest need.

5. Map any potential water trade-offs associated with FGI (e.g. water bodies failing due to poor quantitative status or inadequate flows) and use mapped sensitivities to guide tree planting design and management to minimise disbenefits (e.g. by changing tree type or species to reduce tree water use).

6. For existing FGI, map data on tree type, species and age to determine opportunities for forest redesign and management, to reduce future risks to forest water protection functions (e.g. from climate change and related effects on the incidence of fires, storms and drought, as well as pest and disease outbreaks).

7. Use findings to amend and integrate FGI, water, flood and related strategies and plans to deliver a more effective, catchment-based approach to tackling diffuse pollution and achieving WFD objectives.

\subsection{How Can FGI Help?}

Forests are widely recognised as the preferred land cover for protecting water supplies. This reflects a range of attributes, including the ability of forest canopies to moderate rainfall inputs due to wet canopy evaporation; the well-structured nature of forest soils resulting from sustained organic matter inputs, tree rooting and lack of soil disturbance, reducing erodibility and promoting slope stability; active uptake and tight canopy recycling of nutrients; and the generally very low level of chemical inputs to forests such as fertilisers or pesticides (Nisbet et al. 2011; Creed and Noordvijk 2018). Consequently, waters draining forests are typically of high quality and good ecological condition, requiring little or no treatment for public water supply.

Historic clearance of forests for agriculture has resulted in the widespread loss of these water benefits and a shift to a more intensive land use often associated with frequent soil disturbance, soil damage, increased erosion and high inputs of nutrients and chemicals. Despite recent improvements to farming practice, many agricultural activities typically generate significant losses of sediment, nitrate, phosphate, pesticides and/or FIO to the water environment. These result in diffuse pollution and cause a large number of water bodies to fail to achieve good ecological status. Food scarcity may prevent large-scale forest replanting to tackle the issue, but there is significant scope for FGI in the form of targeted, small-scale, woodland planting on agricultural land to make a difference. This includes the use of agroforestry, 
shelterbelts and tree-lined hedges to help capture and remove diffuse pollutants from adjoining arable crops or livestock pasture.

Targeted planting works because the sources of pollutants, the pathways by which they move to watercourses and the vulnerability of downstream water users are spatially variable (Fig. 8.4). For example, soils vary in their vulnerability to damage, ability to retain nutrients and chemicals, propensity to generate rapid surface runoff and degree of connectivity to watercourses. Once pollutants are mobilised in water or the air, they tend to move along preferred pathways such as surface channels, drains/ditches and the prevailing wind direction. Water receptors such as groundwater boreholes draw water from distinct areas and depths of ground. Tree planting on, around, across or along these key pollutant sources, pathways

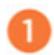

\section{ALONG WATERCOURSES}

Tree planting provides a protective buffer from management activities on the adjacent land, reducing nutrient, sediment, pesticide and $\mathrm{FIO}$ inputs to water. A tree cover also provides much needed shade and cooling of watercourses, while tree roots strengthen banksides and reduce channel erosion and siltation.

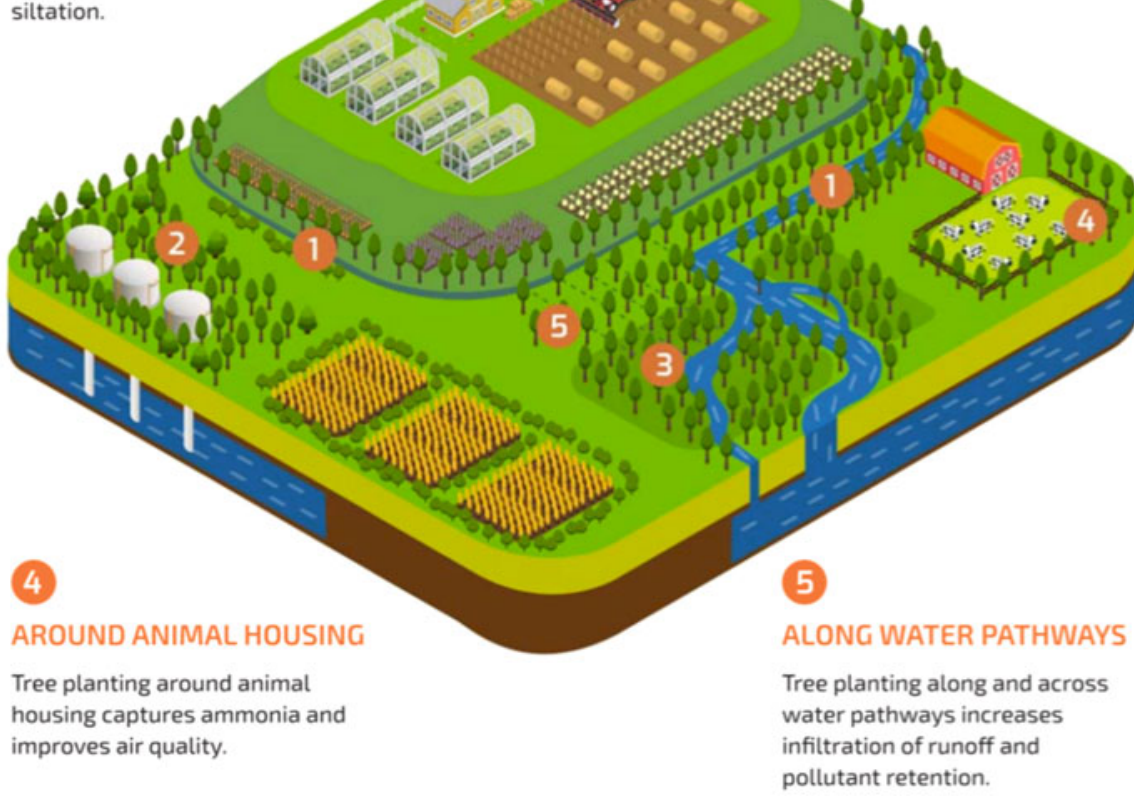

Fig. 8.4 Preferred locations in a farmed landscape for tree planting to reduce diffuse pollution 
and receptors can potentially be very effective at reducing pollutant delivery to watercourses and water supplies, thereby markedly improving water quality for a limited land take.

Planting across or along pollutant pathways in the form of buffer areas or strips offers a dual water quality benefit (Fig. 8.4). Firstly, the pollutant input associated with the previous agricultural activity on this sensitive area of ground will be removed. Secondly, there is a significant opportunity for the planted trees to act as a barrier to the movement of pollutants from upslope or upwind (Ucar and Hall 2001). Pollutants can be retained or removed by runoff being encouraged to infiltrate into the better structured soil of the buffer; by filtration and surface deposition as surface runoff passes through the leaf litter layer or is held in surface depressions created by tree roots; by root uptake and incorporation into growing trees; or by interception and capture as the polluted airflow passes through the tree canopy. Riparian woodland buffers have the added benefit of removing pollutant inputs and reducing damage to this very vulnerable and connected area of land, as well as providing scope for planted trees to remove pollutants carried downstream within the main watercourse during out-of-bank flows.

WFD monitoring data show a marked difference in water quality between forest and agricultural land uses, with the magnitude of difference depending on the intensity and quality of land management. The quantity of pollutant inputs in the form of fertiliser, organic amendments and chemicals and typical exports in surface runoff or leaching to groundwater are well known for each land use and can be used by pollutant models to estimate the impact and effectiveness of a given area of landuse change (Table 8.1). In contrast, it is more difficult to predict the barrier effect of buffer areas since this is influenced by many design and management factors, as well as by the nature and type of pollutant and the scale of intervention. However, studies have shown that with good design and appropriate management, tree buffer areas can be highly effective at reducing pollutant delivery in surface runoff from upslope land, with efficiencies of up to $100 \%$ possible for certain pollutants (PerezSilos 2017).

A review of 65 studies found buffer width to be a dominant factor, with pollutant removal generally decreasing with declining buffer width (Perez-Silos 2017). There are a number of important factors that act to reduce the efficiency by which tree buffers can remove diffuse pollutants from upslope land. These include increasing volume of runoff, increasing pollutant load (especially if the quantity of pollutant draining from upslope land exceeds the capacity of the trees and soil to remove or process it), the presence of newly established/very young or old trees, poor tree condition or weak tree growth, wider tree spacing and the presence of any bypass channels such as drains. Great care is therefore required in the design and management of buffer areas to cope with local pollutant loads and to efficiently achieve and maintain high levels of pollutant removal. This may require productive woodland management and regular harvesting to sustain nutrient uptake (see Sect. 8.5).

Landowner pressure to minimise land take from agriculture acts as a major constraint on buffer width that can result in suboptimal performance. As a rough 
8 Forest Green Infrastructure to Protect Water Quality: A Step-by-Step Guide. . .

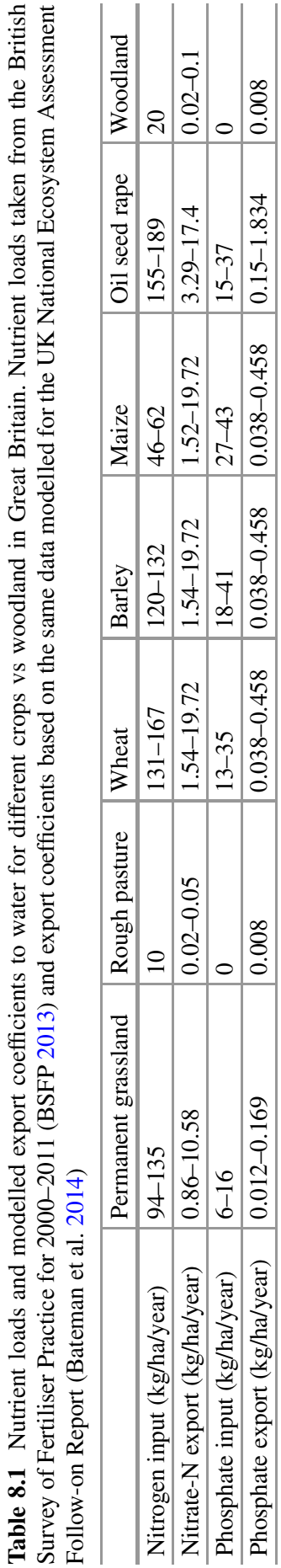


Table 8.2 Per cent reduction in diffuse pollutant concentration in surface runoff from upslope land to watercourses achievable from a well-designed and managed woodland buffer of variable width. Interpolated from relationships derived from review by Perez-Silos (2017)

\begin{tabular}{l|l|l|l|l|l}
\hline Buffer width & $5 \mathrm{~m}$ & $10 \mathrm{~m}$ & $20 \mathrm{~m}$ & $50 \mathrm{~m}$ & $100 \mathrm{~m}$ \\
\hline Nitrate-N & $20 \%$ & $30 \%$ & $40 \%$ & $80 \%$ & $90+\%$ \\
\hline Phosphate-P & $10 \%$ & $20 \%$ & $30 \%$ & $60 \%$ & $90+\%$ \\
\hline Suspended sediment & $80 \%$ & $90+\%$ & $90+\%$ & $90+\%$ & $90+\%$ \\
\hline
\end{tabular}

guide, Table 8.2 shows what could be expected in terms of reduction in different diffuse pollutants in surface runoff from upslope land by an increasing width of a well-designed and managed woodland buffer, based on a recent review (Perez-Silos 2017). Data are lacking for FIO and many pesticides, with removal efficiency for the latter greatly depending on the type of pesticide and its pathway of movement.

While the above tables can be used to explore the environmental effectiveness of woodland planting compared to other measures and help underpin rough costeffectiveness estimates, the design of a scheme and especially one that seeks to make a difference at the catchment level is best informed by hydrological modelling. Understanding soil and hydrological processes is crucial to identifying pollutant sources and pathways for correct targeting of measures, as well as for quantifying and upscaling their environmental effectiveness. It is important to use a spatially distributed model that can be incorporated within GIS to determine the most effective placement and integration of measures, accounting for dynamics in pollutant movement and the evolution of measures. The physically based Soil and Water Assessment Tool (SWAT) model is often preferred for such applications, although it is highly data demanding, is unsuited to very small catchments $(<150 \mathrm{ha})$ and requires great care to ensure correct model parameterisation, especially in relation to forest processes (Baksic 2018). A groundwater model would be needed to predict the movement of pollutants to deep boreholes. Where resources and data are lacking to allow process modelling, more simple tools can be applied such as the Integrated Valuation of Ecosystem Services and Tradeoffs (InVEST) suite of models (Kareiva et al. 2011).

\subsection{Importance of Design and Management of FGI}

The benefits of tree planting for water can evolve over a number of years due to the time taken for trees to grow, a forest canopy to form and the associated effects on water use and soil improvements to become fully established. There can also be a significant lag before soil stocks of nutrients or contaminants such as pesticides from the previous land-use breakdown, or are washed out of the soil-rock system. The delay and lag time will vary with type of pollutant, the depth of water pathways (being much slower for deeper groundwater) and the nature of tree planting (e.g. tree type, species and stocking density). For example, reductions in suspended sediment, 
adsorbed/total phosphate and FIO can be rapidly delivered (within 1-3 years) by the cessation of soil disturbance, removal of livestock and improvement in soil infiltration with tree rooting following planting. In contrast, while there will be a rapid step-change in nitrate and pesticide inputs following land-use change, soil and groundwater stocks of these chemicals can take decades to be removed from groundwater supplies.

A particular advantage of tree planting is the semi-permanent nature of the landuse change such that water benefits can be secured in the long term. However, this relies on planted trees and established woodlands and forests being sustainably managed and replanted if felled or lost to fire, storms or pest and disease. Productive management can provide economic benefits to landowners and managers in the form of timber and wood fuel but poses risks of pollution due to forestry operations such as timber harvesting and extraction, as well as the temporary loss of water benefits until trees regrow after felling. These risks can be minimised through good forestry practice but require great care in forest planning, design and management, especially involving sensitive locations such as riparian buffers (Forestry Commission 2019).

The targeted planting of woodland buffers for intercepting diffuse pollutants from adjacent agricultural land requires more detailed design and active management to sustain and promote pollutant removal. The technical specification will vary between sites and needs to be determined on a case-by-case basis, with woodland design tailored to site type, the nature of the pollutant and its pathway of movement. For example, sediment trapping is enhanced by creating a vegetated and rough ground surface that benefits from less canopy shade and wider tree spacing. In contrast, nitrate removal either requires wet woodland with waterlogged soils to promote nitrate loss by denitrification (note that this increases nitrous oxide emissions, a potent greenhouse gas (GHG)) or planting close-spaced, faster growing tree species to maximise nitrate uptake. Where nitrate inputs in surface runoff from upslope land are very high, regular harvesting of timber or wood fuel may be necessary to avoid nitrate saturation and overloading buffers. In such cases, wider buffers would facilitate phased harvesting of strips to maintain some degree of nitrate removal, although particular care is required to avoid ground damage during operations.

Other pollutants such as ammonia and pesticides that are dispersed via aerial pathways require special attention to the design of the structure of the woodland canopy to maximise aerial deposition and pollutant trapping. A typical example is the design of woodland buffers around animal housing to reduce ammonia emissions (Bealey et al. 2016). Another issue can be the presence of drains or soil fissures that allow pollutants in drainage waters to bypass the soil and the potential for soil retention and root uptake. This may require physical interventions to disrupt these pathways such as by drain blocking, although blockage can also occur naturally over time by tree rooting or soil shrinkage and swelling (Stutter et al. 2020).

Some view leaving FGI unmanaged to be a more attractive option for securing water benefits, but this is increasingly challenged by climate change and associated risks of storm, fire and disease outbreaks. Managing these risks is driving the need for greater intervention to increase tree species and age diversity or install fire 
breaks to enhance forest resilience, especially in forests where historic management has left relatively even-aged or single species stands. Examples include extensive forest conversion from conifer to broadleaves in areas of Germany as spruce and pine stands are increasingly impacted by pests and disease (Schuller et al. 2011), and the installation of forest-fire prevention measures in parts of France. However, the absence of productive management in some forests makes such interventions uneconomic for forest owners necessitating economic support.

\subsection{Managing Potential Disbenefits}

While FGI is generally very good for protecting water quality, there is one common potential disbenefit. This relates to the ability of trees to use more water than shorter types of vegetation, resulting in less water runoff or recharge (e.g. due to interception/wet canopy evaporation and/or potentially higher transpiration rates sustained by deeper rooting) (Nisbet 2005). The subject is complex, is widely researched and still attracts debate. Much depends on a wide range of site factors, especially geographical scale, climate, altitude, geology, soil type, forest type, tree species, tree age and the counterfactual land cover. In general: conifers reduce water yield more than broadleaves; differences between individual species tend to be small (although with a few exceptions); reductions are much less for very young and old trees; and the impact on catchment water yield is relatively limited (difficult to measure) when less than $20 \%$ of a catchment is planted or cleared of forest (Creed and Noordvijk 2018).

In some locations, forests can have the opposite effect and increase water yield. Notable examples include high altitude forests that are effective in trapping cloud water, the planting of broadleaved forest on grassland overlying chalk geology and where forests replace irrigated agriculture or crops with a high water use (Creed and Noordvijk 2018; Roberts and Rosier 2005). The water use of an existing forest can be reduced by changing forest type from conifers to broadleaves, diversifying forest age and introducing more open space, although these represent a significant cost to forest owners.

The water-use issue becomes further complicated concerning the impact of forests on dry weather flows, when water supplies are most limiting. The generally greater water use by trees can be expected to reduce low flows but much depends on the nature of local soils and geology. Permeable geologies are the most vulnerable, while reductions can be expected to be small or even reversed on impermeable geologies with poorly structured soils. Here, tree planting can improve soil infiltration leading to a greater proportion of net rainfall draining to depth and supplementing low flows. Another exception concerns the presence of riparian and floodplain woodland, which can enhance the storage of flood waters and their subsequent release, helping maintain dry season flows. A further complicating factor is that the higher water use and potential water yield reduction by forests can 
be beneficial for reducing flood flows in flood risk catchments and tackling soil salinisation issues in dryland environments.

Models (e.g. SWAT, WaSSI-C, Hydro-JULES) are available to estimate the effect of FGI on water yield, but these vary in their ability to represent and handle key forest hydrological processes (e.g. wet canopy evaporation), as well as forest design and management factors. Great care is therefore required in selecting appropriate models and parameter values, as well as making a serious effort to test and validate model predictions. Modelling impacts on extreme flows is the most difficult.

Other potential water disbenefits tend to be more localised in extent and include the risk of increased water acidification and mobilisation of metals such as aluminium due to forest canopy scavenging of acid deposition. This issue is largely limited to acid-sensitive, upland geologies and rapidly declining due to EU success in emission control (Nisbet and Evans 2014). Another issue is excessive canopy shade and poor channel morphology resulting from conifer plantations located too close to watercourses. Care is also required to avoid the build-up of captured pollutants in tree biomass or in the soil, which could be released back to the water environment. Lastly, while tree planting and forest cover generally act to reduce flood risk, there are some localised exceptions, such as the backing-up of floodwaters upstream of floodplain woodland and the blocking of culverts and bridges by the washout of woody material (Nisbet et al. 2011).

All above potential disbenefits can be effectively managed by good design and management of FGI, especially by planting the most appropriate type and species of tree in the right place based on site factors and ecological requirements.

\subsection{Identifying and Assessing Multiple Benefits}

While the emphasis of this chapter is on how FGI can protect and improve water quality, it is important to recognise that this strategy will also increase natural capital and deliver multiple benefits (from the so-called ecosystem services) for other policy agendas. There is particular scope for FGI to reduce downstream flood risk as well as ameliorate rising water temperatures through shade provision, which are topics of growing concern in the context of climate change (Burgess-Gamble et al. 2017). FGI will also directly contribute to climate change mitigation through carbon sequestration and building soil carbon, thereby helping to offset agricultural GHG emissions (Morison et al. 2012). Other notable benefits include improving biodiversity and tackling the decline in woodland birds by increasing woodland habitat and linking-up fragmented woodlands within agricultural landscapes; the provision of timber and wood fuel to diversify agricultural businesses; and the 
potential to improve open landscapes and provide increased access for recreation (Bateman et al. 2014).

\subsection{How to Design a PES Scheme}

There are eight operational steps involved in designing a successful PES scheme, which are described below in the context of using FGI to improve or protect water quality. Schemes can be simple or complex and large or small, depending on the location of interest and nature of the water issue. Three case studies summarising successful schemes are referenced in accompanying text boxes (Boxes 8.2, 8.3, and 8.4), and more information on these can be found via the PESFOR-W web site (www.forestresearch.gov.uk/research/pesforw/case-studies).

1. Defining the water quality issue: This can take a number of forms. For an agricultural area, the water issue could typically be an excessive level of diffuse pollutants generated by farming activities resulting in a failure to achieve water quality standards and good water status. For an existing forest, it could be that its inherent water protection function is threatened by an environmental pressure such as an increased risk of storm damage or fire due to climate change, or spread of a pest or disease. Alternatively, the threat could be posed by agricultural intensification or urban expansion. Whatever the issue, the starting point is to clearly define its nature, including its spatial extent and temporal dimension. In the case of diffuse pollution, there is a need to determine which pollutants (e.g. nitrate, phosphate, sediment, pesticides or FIO) are involved, their sources (e.g. which fields, areas or soils) and pathways of movement (e.g. surface runoff or groundwater). The water regulatory authority will be a key partner in defining the water quality issue.

2. Identifying local actors: This involves identifying all stakeholders linked to and affected by the water issue. In theory, PES schemes can be limited to single buyers and sellers but are more likely to involve a broad range of actors, especially for more extensive water issues. Local actors can be categorised into five main groups: regulatory bodies, suppliers and sellers, beneficiaries and buyers, intermediaries and designers (Fig. 8.5). Regulatory bodies or beneficiaries and buyers are more likely to take the lead in developing a PES scheme, while work will be required to raise awareness of the water issue amongst some actors and to persuade them to fully engage.

3. Assessing the feasibility of a PES scheme: Bring together stakeholders to explore the water quality issue and consider potential solutions and opportunities, drawing on wider experience and examples of different PES schemes. Assess the existing water quality baseline and margin of improvement needed to meet a water quality target or standard, or in the case of the loss of an existing forest protection function, the degree of damage likely to be caused. Check that the issue cannot be addressed by good management practices, or regulatory 


\section{THE MAIN ACTORS}

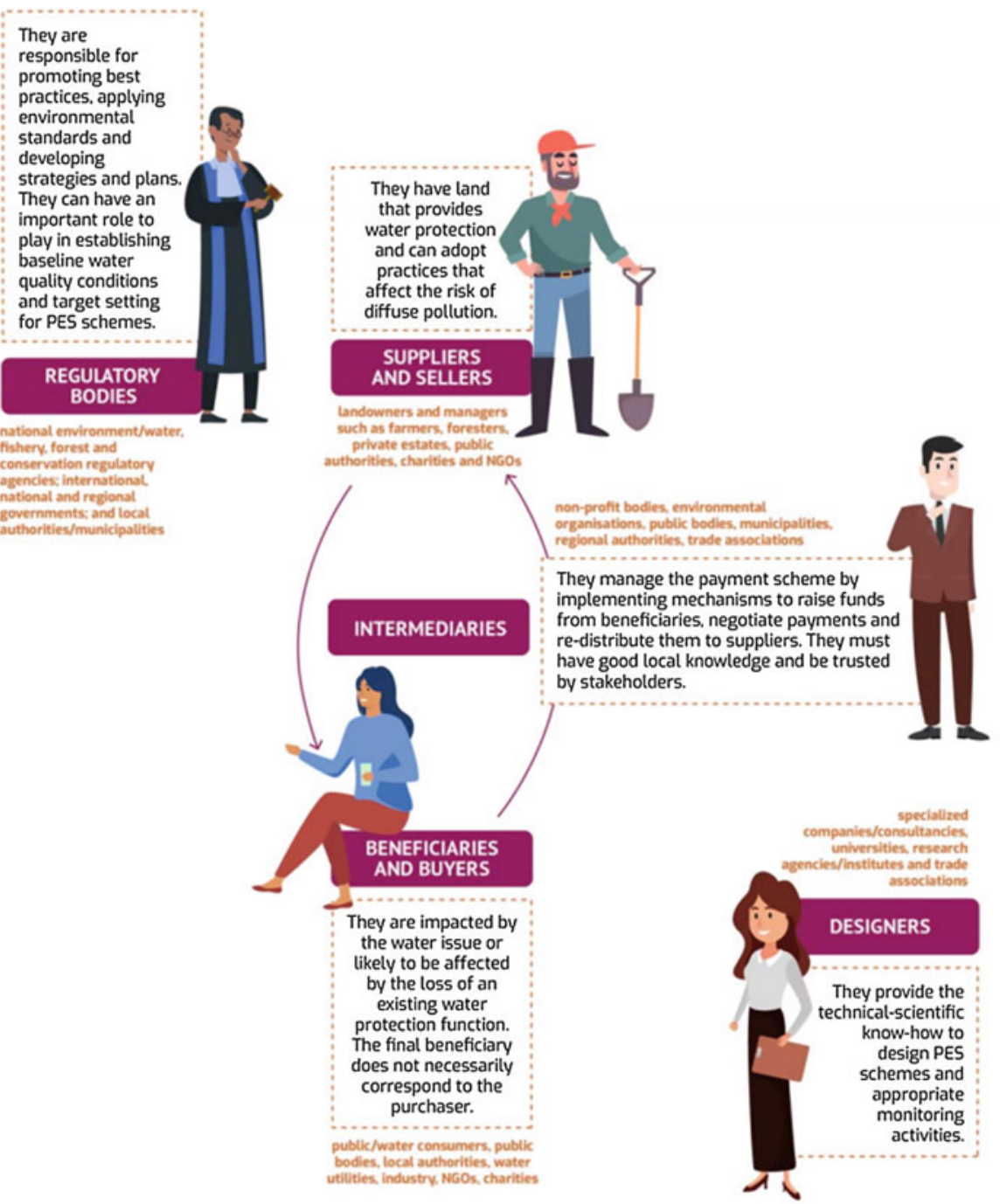

Fig. 8.5 Main actors who may be involved in designing a PES scheme

mechanisms. Examine the alternative measures that could be adopted, exploring how costs, benefits and avoided risks differ between them and according to the extent to which they are used, and identify the least cost and most acceptable option. Establish whether there are willing buyers and sellers to implement and finance the preferred measures, a desire to collaborate amongst actors, and trusted 
intermediaries to assist with organising and managing a PES scheme. If so, assess transaction, management and monitoring costs.

4. Exploring potential win-win solutions: Consider whether the identified option(s) will deliver additional benefits from ecosystem services (e.g. for carbon sequestration, flood risk management, recreation and biodiversity [see CICES (HainesYoung and Potschin 2017)] and if so, whether there is a market for these. Where there is a willing buyer, try to quantify the potential benefits and assess the scope to develop an integrated scheme that also considers these other ecosystem services and impacts on natural capital. To help design the PES scheme, underpin investment decisions and increase public support, a comparative cost-effectiveness analysis of the per unit environmental improvement can be undertaken by intermediaries or designers where data are available (Box 8.5).

5. Defining roles and responsibilities: Providing there is local support for developing a PES scheme, define roles and responsibilities of key actors. This should include setting clear spatial boundaries for the scheme and agreeing measures, associated costs, payments and timelines. Seek and draft agreements.

6. Resolving or minimising potential legal issues: Consider legal, fiscal and regulatory issues for key actors, such as implications for taxes, property rights and pollution control, especially for those making or receiving payments. Where necessary, legal advice should be sought to aid decision making.

7. Drawing-up technical specifications: Technical specifications should be developed and agreed for the design and management of the selected measure(s) to address the water quality issue. Regulatory bodies and designers are usually best placed to advise on the required specification. For tree planting, this will vary from site to site and include consideration of location (e.g. local climate, geology, soils and topography), extent/area or width of planting (see Table 8.2), tree type, species mix, planting density, timing and required management practices to ensure effective tree establishment and growth (e.g. ground preparation, weed control and fencing). For an existing forest, it could involve elements of forest redesign to reduce risks or improve resilience, such as changing forest type or species mix, altering age structure or introducing fire breaks. The specification should build-in some leeway (e.g. extra tree planting) to allow for uncertainty in the effectiveness of a given measure.

8. Formalising scheme contract: A formal contract should be drawn up between buyers and sellers, covering the technical specification for measures to be implemented, timelines for delivery, baseline water quality conditions, success criteria, monitoring needs, staged payments and scheduled reviews. However, it is best to incorporate a degree of flexibility in the Terms and Conditions to allow for future adjustments informed by monitoring and evaluation. Care is required to avoid a high level of bureaucracy and transaction costs, ensuring that scheme management and monitoring are fit for purpose. 


\section{Box 8.2 Case Study: Tree Planting to Secure Water Benefits}

Globally, many water utilities are increasingly recognising the growing threats to water supplies and rising cost of water treatment. Consequently, attention is shifting away from grey to green infrastructure to better secure future water quality and quantity in source catchments. PES schemes are emerging as a more sustainable approach to water management whereby landowners such as farmers and forest owners are incentivised to change land use or management to better protect water supplies. Targeted measures such as tree planting within safeguard zones potentially offer a more cost-effective way of addressing diffuse water pollution issues compared to water treatment. At the European Level, Article 9 of the WFD stipulates that 'Member States shall take account of the principle of recovery of the costs of water services, including Environmental and Resource Costs'. This has led to some water utilities in the UK (South West Water and United Utilities), Germany (Saxony and Hanover) and Italy (ETRA and Romagna Acque) to charge consumers for the costs incurred in source area protection, with payments passed onto landowners and managers. These schemes are sometimes characterised as 'PES-like' as consumers are not voluntarily paying for the benefit/bill; however, they have proven to be the most effective systems at EU level for improving water quality at the catchment level (UNECE 2018).

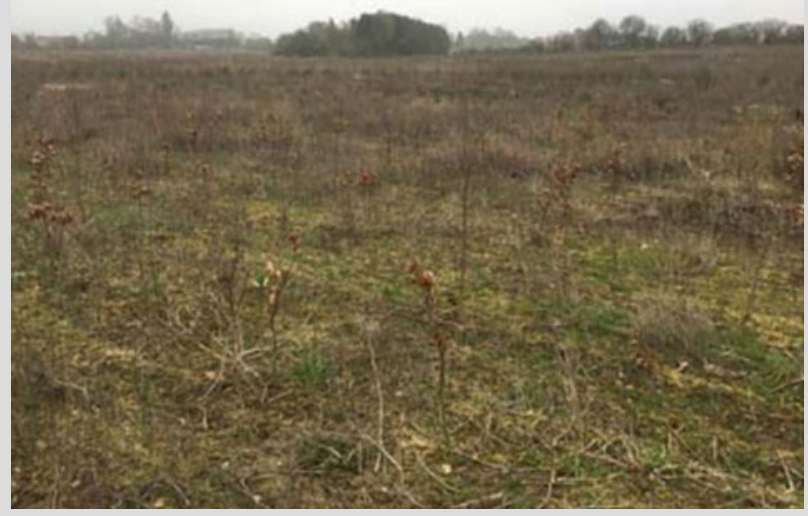




\section{Box 8.3 Case Study: Tree Planting to Protect Groundwater Quality}

There are three notable woodlands for water PES schemes in Denmark. Two of these are located near Odense on Funen and the third near Aalborg on Jutland. All are designed to tackle the growing issue of groundwater pollution by agricultural practices, especially the contamination of drinking water by rising nitrate and/or pesticide levels. The scheme at Aalborg is one of the oldest and established in 1991 with funding from EU LIFE and the Aalborg Municipality to purchase land from farmers within vulnerable groundwater recharge zones. 900 ha of intensive farmland were converted into 500 ha of broadleaved woodland and 400 ha of low-input pasture, primarily to reduce nitrate levels. The drinking water benefit was estimated at a minimum of $€ 489 /$ ha/year and the net social benefit (excluding drinking water) at $€ 189 /$ ha/year, which included the provision of local recreation and carbon gain. The two schemes near Odense are Elmelund Skov and Brylle Water, both of which involve woodland creation to reduce pesticide pollution of local groundwater supplies. This is achieved by a voluntary process of land consolidation whereby agricultural land is purchased in low vulnerable areas and used to encourage land swaps with farmers for land within vulnerable groundwater recharge zones. The land is transferred to public or private partners at a reduced price for woodland planting and management, with a permanent change from farmland to forest legally guaranteed. At Elmelund Skov, 380 ha of farmland have been converted to woodland since 2001 under a partnership agreement between the local water utility, the Odense Municipality and the state forestry agency. The Brylle Water scheme is the most recent and commenced in 2014. 156 ha of farmland were purchased and planted with woodland by a private foundation, who met $40 \%$ of the cost, with the other $60 \%$ funded by the local water utility. The land consolidation process involved a significant transaction cost in negotiating agreements with farmers and building trust. Public access for recreation was a strong component of the schemes and underpinned municipality funding and support.

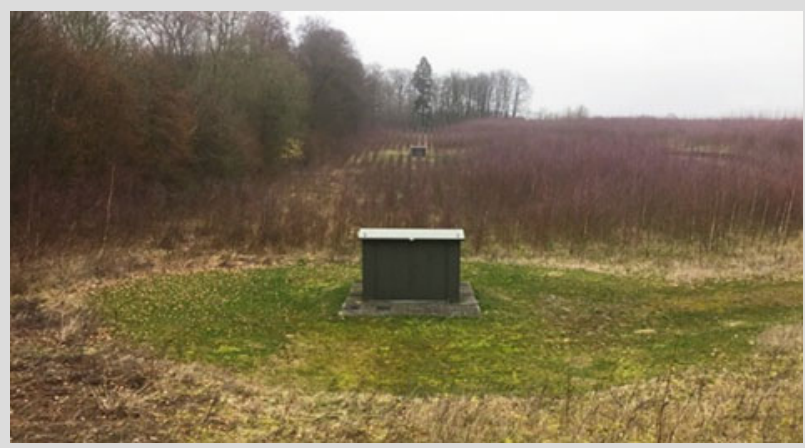




\section{Box 8.4 Case Study: Tree Planting to Improve Groundwater Infiltration}

This PES scheme is located on the edge of the town of Carmignano di Brenta, near Padua in northern Italy. It was established in 2012 as a 'Forested Infiltration Area' (FIA) to help replenish and improve groundwater resources in the area. Overexploitation of the aquifer had led to the disappearance of local springs and streams, while agricultural activities had degraded groundwater quality. A 2.5 ha broadleaved woodland was planted on arable (maize) land and a system of trenches dug to channel surface water (at a rate of $\sim 1$ million cubic metres per hectare per year) onto the site during periods of excess flow in the nearby River Brenta. The establishment of the woodland helped to facilitate water infiltration into the aquifer and enhanced phyto-purification, removing nutrients and other contaminants. The woodland also provided a carbon gain to the landowner and woodland products such as firewood, biomass and timber in the longer term, as well as benefiting the local community as a valuable habitat and opportunities for recreation and education. A group of local and regional stakeholders, including municipalities and local companies, formed a partnership to bid for supporting funds that were used to design and set up the PES scheme on private farmland. Around $80 \%$ of implementation costs were financed by LIFE+ and RDP funds. The loss of income to the landowner from the change in use from maize cropping to woodland was exceeded by payments from the Brenta Land Reclamation Board for the infiltration water service ( $€ 1200 /$ ha/year), the municipality for community access and related recreation and education events ( $€ 1500 /$ year), plus the value of generated wood products and carbon gain.
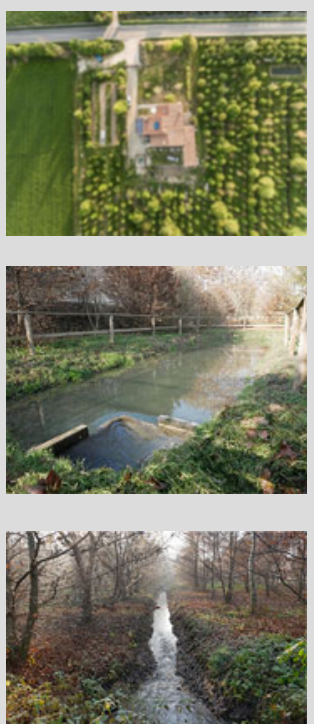


\section{Box 8.5 Cost-Effectiveness Analysis (CEA)}

Cost-effectiveness analysis (CEA) is a technique that can be used to compare the cost of FGI with that of alternative measures for improving water quality. It can be important both in making a case to adopt woodland planting and in selecting which woodland (and/or other) measures to implement. The main challenge is to estimate how much planting and/or the extent of an alternative measure is required to achieve a given water quality target. It is easiest to focus on a specific diffuse pollutant or set of pollutants such as reducing the concentration of nitrate in a watercourse by $\mathrm{X} \%$ or to below an environmental standard, rather than adopting a broader water quality index like 'water status' or using a biological metric. The assessment is likely to require the use of a spatially distributed model such as SWAT to estimate the effect of different levels and locations of planting on water quality, as described in Sect. 8.5. An alternative, simpler approach would be to limit consideration to the effect of alternative measures on pollutant loads, with values for the latter relatively well known for different land covers and crop types (Table 8.1). In cases where measures are proposed in order to reduce the risk of infringing water quality targets that are currently met, the improvement would need to be considered in terms of the reduced risk of exceeding this target.

Cost-effectiveness analysis (CEA) involves dividing the cost of the woodland planting or other measure by the improvement/gain made in water quality. Depending on whether a reduction in concentration or load is the focus, the cost-effectiveness ratio (RCE) computed may be expressed in units such as $€ / \mathrm{mg} / \mathrm{l}$ or $€ / \mathrm{kg} / \mathrm{ha}$ of a given pollutant. The aggregate cost should be computed by discounting costs in future years over the lifespan of the FGI. The costs need to include the revenue forgone from the change in land use and any transaction costs. Where a private sector perspective is adopted, the costs should also include any changes in financial incentives involved. However, where CEA is undertaken from a societal perspective, changes in subsidy payments (e.g. associated with EU agri-environmental schemes) should be excluded because these are considered transfer payments. Although the focus here is on water quality, the value of other benefits generated by the woodland can also be included in the calculation and used to offset the cost, so reducing the RCE. This can be a challenging task for some benefits such as habitat gain but easier for others like carbon sequestration.

Key steps involved in CEA are:

- Identify the water quality issue and level of required improvement, such as in the concentration or load of a specific diffuse pollutant to meet or contribute to achieving a given water quality standard.

- Estimate the amount of FGI and other alternative measures needed to deliver the desired reduction in pollutant concentration or load using mod- 
elling (e.g. SWAT) or pollutant budgeting. Calculate the aggregate cost of implementing the measures, including revenue forgone, transaction costs and (for a private sector perspective) incentives, discounting management and other costs expected to arise in the future over the lifespan of the measures.

- In cases where the expected changes in measure effectiveness over time differ between measures, one of two approaches should be adopted: either divide the aggregate costs by an environmental benefit index that weights future environmental improvements according to when they are expected to arise (e.g. by applying a discount rate to improvements in future years) or compare measures using a benchmark cost-effectiveness cost-comparator that takes account of when improvements arise (an approach sometimes used in comparing options for climate change mitigation-e.g. DBEIS 2019).

- Consider other benefits and any disbenefits provided by the measures or by the original land use and where feasible, estimate the value or costs of these (similarly by applying a discount rate to those arising in future years), to compute the net cost of each measure.

- Taking into account the above net costs and environmental effectiveness of potential measures, including an allowance for risk and uncertainty, calculate the average and range of the RCE for each measure and compare performance. Marginal Abatement Cost Curves can be used to explore the relationship between the cost-effectiveness of different measures and the total amount of diffuse pollution abated at specific points in the future.

- Use results to design an appropriate payment scheme to deliver the least-cost measure or mix of measures to meet and secure water quality target(s) within a given timeframe, taking account of local suitability and acceptability of measure(s).

- Where attracting a range of investors for FGI is important, consider computing cost-effectiveness from other perspectives too (e.g. climate change mitigation and/or flood risk attenuation).

- It is important to keep all relevant documentation detailing calculations to inform future review and learning.

\subsection{Monitoring, Evaluation and Review}

Monitoring can take many forms that vary greatly in cost. Firstly, implemented measures will require a certain level of monitoring to ensure that they are designed as planned and managed appropriately to deliver and maintain their effectiveness in pollutant reduction. For FGI, this includes checking that the trees become fully 
established (e.g. replacing any losses and managing grazing and potential weed and pest issues) and that the established woodland is sustainably managed and, where appropriate, the woodland replanted to secure long-term effectiveness. In the case of more targeted planting such as in the form of riparian woodland buffer areas, there is a need to check that these are designed and managed appropriately to deal with the diffuse pollution issue (and to deliver any co-benefits) over the expected lifespan of the buffer. This includes checking that tree growth rates are sufficient and sustained to deal with nutrient runoff from adjacent land, the buffer does not get overloaded/saturated by the pollutant(s) and any management interventions do not damage the site.

Secondly, in many cases, there will be a need to monitor the water quality response to check that the FGI is having the desired effect. It may be possible to rely on existing monitoring networks (e.g. for WFD assessments) operated by water regulators for this purpose, but these will usually be undertaken at the water body scale and so may need to be supplemented by local measurements. Monitoring needs to be tailored to the nature of the implemented measure, how it will affect diffuse pollutant sources and pathways and the specific pollutant(s) involved. For example, small-scale woodland planting is less likely to justify river water quality monitoring and better suited to conducting plot-based measurements such as changes to soil conditions. There should be agreement on the location, type, frequency and cost of monitoring; data handling, storage and ownership; and on data analysis, reporting and publication of results.

Tackling water body scale diffuse pollution issues is likely to require extended areas of targeted FGI involving multiple landowners and taking multiple years to deliver. This will necessitate strategic planning and integrated catchment management, with regular review of progress and actions. Progress made in achieving water quality targets can be directly linked to contracted payments, although the high temporal variability of water quality parameters (e.g. due to variability in weather conditions and river levels) can make this very challenging, especially over short-medium timescales. Consideration should be given to undertaking a periodic evaluation of the cost-effectiveness of the scheme to inform the need for any changes, share lessons and ultimately ensure long-term success.

\subsection{Spreading the Word}

Successful communication, dissemination and marketing of PES actions are dependent on messages being appropriately targeted to the relevant actors. Levels of awareness and understanding of the benefits of FGI for water will vary greatly between actors, and therefore different approaches and stories may be required. Be aware of different learning styles and tailor information accordingly. Academic approaches that apply in the classroom may not work out in the field. Be sensitive to local conditions and relationships. 
Sources and pathways of diffuse pollution are likely to be disputed, especially amongst landowners and managers, necessitating an open discussion of the evidence and drawing on expert opinion. A number of alternative options for tackling a given water issue will often be available, and those involving land-use change and particularly woodland creation will face inherent resistance by some. Focus on careful targeting of FGI to enhance effectiveness and minimise impact on existing land use.

Bringing different groups together, discussing contrasting viewpoints and resolving differences are critical. Consideration should be given to using a facilitator such as a trusted intermediary, especially where there are deep-seated differences between actors. The use of maps and model outputs can be very helpful but must be handled sensitively and not used to apportion blame. Many will not trust these products and question their ability to reflect reality. Consequently, it is very important to ground truth such information, which is best done by key actors meeting and discussing the issues and proposed countermeasures in the field.

Use should be made of regional and wider case studies to develop options and build confidence and consensus, including by visiting existing demonstration sites where possible (check relevant case studies at www.forestresearch.gov.uk/research/ pesforw/case-studies). These studies can be a great way of showcasing the water and wider benefits of FGI, as well as the protection function of existing forests and threats faced.

Acknowledgements This chapter is based upon work from COST Action CA15206, supported by COST (European Cooperation in Science and Technology). COST is a funding agency for research and innovation networks. Our Actions help connect research initiatives across Europe and enable scientists to grow their ideas by sharing them with their peers. This boosts their research, career and innovation. See www.cost.eu
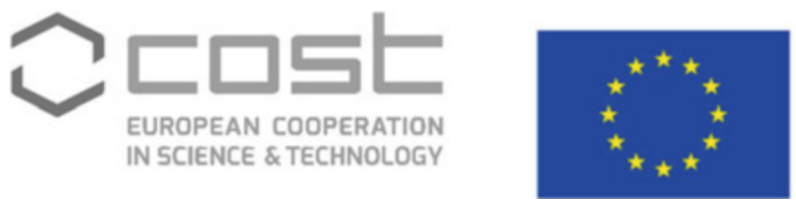

COST is supported by the Horizon 2020 Framework Programme of the European Union

\section{References}

Baksic N (2018) Reviewing available pollutant models and decision support tools for informing the design and management of woodland creation measures for reducing agricultural diffuse pollution. STSM Scientific Report. COST Action 15206. Forest Research, Surrey. 12 pp

Bateman I, Day B, Agarwala M, Bacon P, Bad'ura T, Binner A, De-Gol A, Ditchburn B, Dugdale S, Emmett B, Ferrini S, Carlo Fezzi C, Harwood A, Hillier J, Hiscock K, Hulme M, Jackson B, Lovett A, Mackie E, Matthews R, Sen A, Siriwardena G, Smith P, Snowdon P, Sünnenberg G, Vetter S, Vinjili S (2014) UK National Ecosystem Assessment Follow-on. Work package report 3: economic value of ecosystem services. UNEP-WCMC, LWEC, UK, $246 \mathrm{pp}$

Bealey WJ, Dore AJ, Dragosits U, Reis S, Reay DS, Sutton MA (2016) The potential for tree planting strategies to reduce local and regional ecosystem impacts of agricultural ammonia emissions. J Environ Manag 165:106-116 
Broadmeadow S, Nisbet T (2012) National map of woodland creation opportunities: targeting eWGS to help meet the objectives of the WFD and reduce flood risk in England. Final Report to Forestry Commission England. Forest Research, Alice Holt Lodge, Farnham, Surrey. 29 pp

BSFP (2013) British survey of fertiliser practice dataset. From Department for Environment, Food \& Rural Affairs, London

Burgess-Gamble L, Ngai R, Wilkinson M, Nisbet T, Pontee N, Harvey R, Kipling K, Addy S, Rose S, Maslen S, Jay H, Nicholson A, Page T, Jonczyk J, Quinn P (2017) Working with natural processes_-evidence directory. Environment Agency, Bristol. 298 pp

Collins AL, Newell Price JP, Zhang Y, Godday R, Naden PS, Skirvin D (2018) Assessing the potential impacts of a revised set of on-farm nutrient and sediment 'basic' control measures for reducing agricultural diffuse pollution across England. Sci Total Environ 621:1499-1511

Creed IF, Noordvijk Mv (eds) (2018) Forest and water on a changing planet: vulnerability, adaptation and governance opportunities. A global assessment report, IUFRO World Series, vol 38. IUFRO, Vienna. $192 \mathrm{pp}$

DBEIS (2019) Valuation of energy use and greenhouse gas. Supplementary guidance to the HM Treasury Green Book on Appraisal and Evaluation in Central Government. Department of Business, Energy and Industrial Strategy, London. https://assets.publishing.service.gov.uk/ government/uploads/system/uploads/attachment_data/file/794737/valuation-of-energy-useand-greenhouse-gas-emissions-for-appraisal-2018.pdf

EEA (2016) Annual indicator report series (AIRES): surface waters. EEA Environmental Indicator Report No 30/2016. EEA, Copenhagen

EEA (2018) European waters-assessment of status and pressures 2018. European Environment Agency EEA Report 7/2018. EEA, Copenhagen. https://www.eea.europa.eu/publications/stateof-water

Forest Europe (2019) Valuation and payments for forest ecosystem services in the pan-European region. Final report of the forest Europe Expert Group on valuation and payments for forest ecosystem services. Forest Europe, Bratislava. https://foresteurope.org/publications/

Forestry Commission (2019) Managing forest operations to protect the water environment. Forestry Commission Practice Guide, Forestry Commission, Edinburgh, 48 pp

Gatto P, Pettenella D, Secco L (2009) Payments for forest environmental services: organisational models and related experiences in Italy. iForest-Biogeosci Forest 2(4):133-139

Haines-Young R, Potschin MB (2017) Common International Classification of Ecosystem Services (CICES) V5.1 and guidance on the application of the revised structure. www.cices.eu

Kareiva P, Tallis H, Ricketts TH, Daily GC, Polasky S (2011) Natural capital: theory and practice of mapping ecosystem services. Oxford University Press, Oxford

Mockler AEM, Bruen M (2018) Support tools for characterisation and evaluation of programmes of measures. Report no. 249. Environment Protection Agency, Dublin

Morison J, Matthews R, Miller G, Perks M, Randle T, Vanguelova E, White M, Yamulki S (2012) Understanding the carbon and greenhouse gas balance of forests in Great Britain. Forestry Commission research report. Forestry Commission, Edinburgh. $149 \mathrm{pp}$

Nisbet TR (2005) Water use by trees. Forestry Commission Information Note 65. Forestry Commission, Edinburgh

Nisbet TR, Evans CD (2014) Forestry and surface water acidification. Forestry Commission research note 16. Forestry Commission, Edinburgh

Nisbet T, Silgram M, Morrow K, Broadmeadow S (2011) Woodland for water: Woodland measures for meeting Water Framework Directive objectives. Forest Research Monograph 4. Forest Research, Surrey. $156 \mathrm{pp}$

Perez-Silos I (2017) Assessing the effectiveness of woodland creation for reducing agricultural diffuse pollution-developing value ranges to create look-up tables. STSM scientific report. COST action 15206. Forest Research, Surrey. $11 \mathrm{pp}$

Roberts J, Rosier P (2005) The impact of broadleaved woodland on water resources in lowland UK: III. The results from Black Wood and Bridgets Farm compared with those from other woodland and grassland sites. Hydrol Earth Syst Sci 9:614-620 
Schuller G, Pfister L, Vohland M, Seeling S, Hill J (2011) Large scale approaches to forest and water interactions. In: Bredemeier M, Cohen S, Godbold D, Lode E, Pichler V, Schleppi P (eds) Forest management and the water cycle: an ecosystem-based approach, Ecological Studies, vol 212. Springer, New York, pp 435-452

Stutter MI, Chardon WJ, Kronvang B (2012) Riparian buffers as a multifunctional management tool in agricultural landscapes: introduction. J Environ Qual 41:297-303

Stutter M, Wilkinson M, Nisbet TR (2020) Improving the benefits from watercourse field margins using 3-D buffers. Environment Agency report. Environment Agency, Bristol

Ucar T, Hall FR (2001) Windbreaks as a pesticide drift mitigation strategy: a review. Pest Manag Sci 57:663-675

UNECE (2018) Forests and water-valuation and payments for forest ecosystem services. UNECE, Geneva. $108 \mathrm{pp}$

Open Access This chapter is licensed under the terms of the Creative Commons Attribution 4.0 International License (http://creativecommons.org/licenses/by/4.0/), which permits use, sharing, adaptation, distribution and reproduction in any medium or format, as long as you give appropriate credit to the original author(s) and the source, provide a link to the Creative Commons license and indicate if changes were made.

The images or other third party material in this chapter are included in the chapter's Creative Commons license, unless indicated otherwise in a credit line to the material. If material is not included in the chapter's Creative Commons license and your intended use is not permitted by statutory regulation or exceeds the permitted use, you will need to obtain permission directly from the copyright holder. 